\title{
Application of low dosage of copper oxide and zinc oxide nanoparticles boosts bacterial and fungal communities in soil
}

\author{
Yang Liu ${ }^{\mathrm{a}}$, Yang Li ${ }^{\mathrm{a}}$, Bo Pan ${ }^{\mathrm{a}, *}$, Xinyue Zhang ${ }^{\mathrm{a}}$, Huang Zhang ${ }^{\mathrm{b}}$, Christian E.W. Steinberg a,c ${ }^{\text {, Hao }}$ Qiu ${ }^{\mathrm{d}}$, \\ Martina G. Vijver ${ }^{\mathrm{e}}$, Willie J.G.M. Peijnenburg ${ }^{\mathrm{e}, \mathrm{f}}$

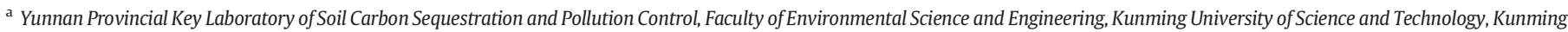 \\ 650500, China \\ ${ }^{\mathrm{b}}$ Faculty of Agriculture and Food, Kunming University of Science and Technology, Kunming 650500, China

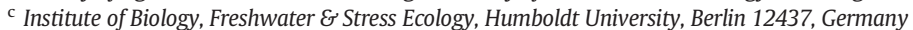 \\ d School of Environmental Science and Engineering, Shanghai Jiao Tong University, Shanghai 200240, China \\ e Institute of Environmental Sciences (CML), Leiden University, Leiden 2300, RA, the Netherlands \\ ${ }^{\mathrm{f}}$ National Institute of Public Health and the Environment (RIVM), Center for Safety of Substances and Products, Bilthoven 3720 BA, the Netherlands
}

\section{H I G H L I G H T S}

- Both $\mathrm{CuO}$ and $\mathrm{ZnO}$ NPs promoted soil microbial community richness and diversity.

- Positive effects of MNPs on soil microbes were impaired at high concentrations.

- Particulate and dissolved forms explained the impacts of MNPs on soil microbes.

- MNPs mixtures showed no additional benefits than the sum of individual effects.

- Positive impact of CuO NPs on soil bacteria was affected by environmental factors.

\section{A R T I C L E I N F O}

\section{Article history:}

Received 27 August 2020

Received in revised form 27 October 2020

Accepted 31 October 2020

Available online 26 November 2020

Editor: Henner Hollert

\section{Keywords:}

CuO NPs

ZnO NPs

Mixture

Soil

Bacteria

Fungi

\section{G R A P H I C A L A B S T R A C T}

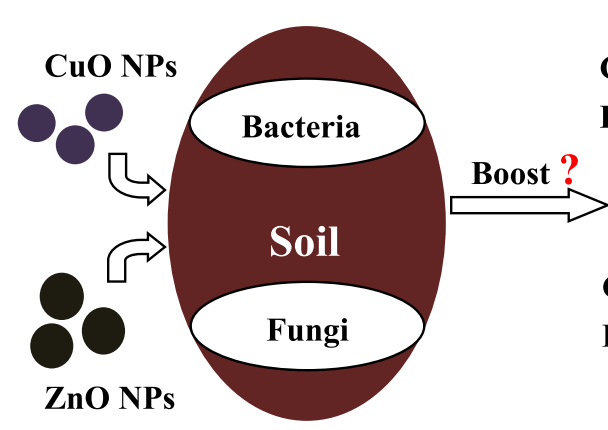

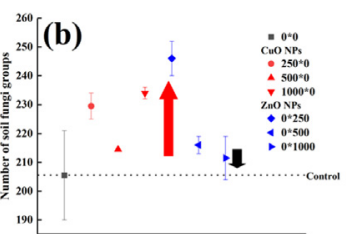

Community

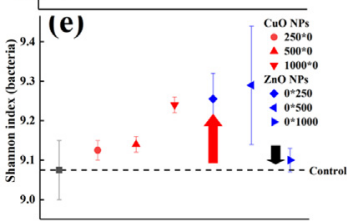

\begin{abstract}
A B S T R A C T
With the expanding nanotechnology, nanoparticles (NPs) embedded products are used in the agricultural sector to improve soil fertility. Thus, two typical metal oxides NPs and their mixtures were applied in different doses to evaluate the impacts on soil microbes. $\mathrm{CuO}$ and ZnO NPs boosted soil microbial communities as reflected by the increased number of extractable bacterial or fungal groups and the enlarged values of Chao 1, ACE, and Shannon indices. Relative abundance of some susceptible taxa such as Sphingomonadales increased with increasing concentrations of ZnO NPs, while IMCC26256 decreased with increasing concentrations of CuO NPs. The mixture of $\mathrm{CuO}$ and $\mathrm{ZnO}$ NPs did not show more promotional effects on the soil bacterial community than the sum of individual effects. Increased soil organic carbon mitigated the impacts on soil bacteria for CuO NPs, but not for ZnO NPs. As micro-nutrients, the ions released from $\mathrm{CuO}$ and $\mathrm{ZnO}$ NPs had the potential to promote soil microbial community richness and diversity. However, the positive impacts of MNPs were impaired at dosage higher than $250 \mathrm{mg} \mathrm{kg}^{-1}$ soil (213.08 $\mathrm{mg} \mathrm{kg}^{-1}$ soil of $\mathrm{Cu}, 162.73 \mathrm{mg} \mathrm{kg}^{-1}$ soil of $\mathrm{Zn}$ ). Thus, the application dose and soil type other than the coexistence of MNPs should be considered before the wide use in increasing agricultural productivity.
\end{abstract}

\footnotetext{
* Corresponding author.

E-mail address: panbocai@gmail.com (B. Pan).
} 


\section{Introduction}

Over the past decade, food insecurity and poverty problems still exist especially in many developing countries despite the fact that tremendous progress has been made in increasing agricultural productivity. One of the promising innovative techniques in agriculture is the application of nanomaterials (FAO/WHO, 2010) in the form of fertilizer or as a pesticide developed on the basis of metal oxides nanoparticles (MNPs) (Asadishad et al., 2018) to achieve higher yields with fewer inputs and less nutrient runoff (Gilbertson et al., 2020). For instance, the addition of $\mathrm{TiO}_{2}$ NPs, ZnO NPs and $\mathrm{CuO}$ NPs has been found to increase the growth and yield of crops probably by stimulating photosynthesis and respiration of plants (Adhikari et al., 2016) or by suppressing the growth of soil pathogens (Rizwan et al., 2017). However, the below ground microbial soil community has received much less attention in improving soil quality and fertility as compared with the above ground diversity and function.

Soil metabolism is closely associated with the growth and development of soil microorganisms (Wyszkowska et al., 2013). As xenobiotics, MNPs can modify soil properties and have a marked impact on soil ecosystems on both population- and community-level. Nevertheless, inconsistencies between studies often occur due to lack of knowledge on the mechanisms of action of MNPs on soil microbes. For instance, some researchers found that foliar ZnO NPs application $\left(10 \mathrm{mg} \mathrm{L}^{-1}\right)$ can significantly increase the rhizospheric microbial population of the legume Cyamopsis tetragonoloba L. likely due to increased secretion of phosphorus-mobilizing enzymes in the rhizophere (Raliya and Tarafdar, 2013). Other papers revealed that neither CuO NPs nor ZnO NPs $\left(1,100 \mathrm{mg} \mathrm{kg}^{-1}\right.$ soil) had significant effect on the bacterial community composition of agricultural soil (Asadishad et al., 2018). In contrast, Ge et al. (2011) showed that ZnO NPs (500 mg kg-1 soil) significantly reduced the biomass and diversity of soil bacteria after 60 days. Similarly, the inhibition efficiency of CuO NPs (500-750 mg kg-1 soil) reached $71-82 \%$ against tomato early blight Alternaria solani (Huang et al., 2015). The above discrepancy of soil microbial responses to even the same type of MNPs could be directly attributed to their different exposure doses. By comparing the applied concentrations above, MNPs seemed to become detrimental to soil bacteria when the concentration was raised from 100 to $500 \mathrm{mg} \mathrm{kg}^{-1}$ soil. Excessive amounts of MNPs may disrupt the homeostasis and physiological functions of microbial cells, denature proteins, destruct cellular membranes, damage metabolic pathways, and subsequently result in the apoptosis of cells ( $\mathrm{Ge}$ et al., 2012; Wyszkowska et al., 2013). Theoretically, harmful impacts on individual (groups of) microbes may consequently decrease the counts and species diversity of soil microorganisms, inhibit the soil processes (e.g. nitrification, ammonification and methane oxidation), reduce the stability or resilience of the soil microbiome to future disturbances (Jansson and Jansson and Hofmockel, 2019), and lead to the reduction of the soil functions (Ge et al., 2012; Wyszkowska et al., 2013). It is thus crucial to systematically assess the soil health and ecosystem functioning in the presence of MNPs through evaluation of the microbial community composition and diversity.

Effects of MNPs may be also related to their state of being or speciation in the soil. Some scientists showed that stronger adverse effects of $\mathrm{CuO}$ NPs on the microbial biomass may be due to their higher solubility or availability as compared with $\mathrm{TiO}_{2}$ NPs (Xu et al., 2015), while others reported that particles dominated the inactivation of microbial activity and functionality (Antisari et al., 2013) because of their small sizes. In our previously published article (Liu et al., 2016), it was found that particulate forms, dissolved forms, and their interactions all contributed to the toxicity of Cu NPs and ZnO NPs to plants. Whether similar results will also occur to soil microbes should be further explored. In addition, the $\mathrm{pH}$ value, water content, and organic matter content may vary a lot in different soils (Lan et al., 2018). The presence of coexistence MNPs (Liu et al., 2016) or organic matter (Xu et al., 2015) may cause the alteration of the chemical behavior of MNPs in different soil environments. Varying environmental factors can thus affect the bioavailability of MNPs to microbial communities via impacts on the agglomeration, sorption, dissolution, and migration of MNPs, which should not be ignored.

Bacteria and fungi as the most diverse groups of living microorganisms, play essential roles in terrestrial ecosystem functioning (e.g. element cycling, waste decomposition), and can be useful for the evaluation of soil's biological activity (Ge et al., 2011; Chen et al., 2017). Thus, the purpose of this study was to systematically investigate the impacts of CuO NPs, ZnO NPs and their mixture on soil bacterial and fungal communities in two typical red soils, and to test the following hypotheses: 1) Relatively lower concentrations of CuO NPs and ZnO NPs (e.g. $<500 \mathrm{mg} \mathrm{kg}^{-1}$ soil as presented above) may promote the soil microbial community richness and diversity. 2) Dissolved and particulate forms can be used to explain the impacts of $\mathrm{CuO}$ NPs and ZnO NPs, while depending on the types of MNPs.

\section{Materials and methods}

\subsection{Characterization of $\mathrm{CuO}$ NPs, ZnO NPs and soil}

Both CuO NPs (spherical, uncoated, purity $>99.5 \%, 40 \mathrm{~nm}$ ) and $\mathrm{ZnO}$ NPs (semispherical, uncoated, purity $>99.8 \%, 50 \pm 10 \mathrm{~nm}$ ) were purchased from Aladdin Industrial Corporation, Shanghai, China. The primary morphology of MNPs were characterized using a Tecnai $G^{2}$ TF30 Transmission Electron Microscope (TEM, FEI Company, Netherland). The characterizations of CuO NPs and ZnO NPs suspended in soil water extract were also conducted (details given in section 2.3).

The soils were collected from a typical red loam soil located at Chenggong District without artificial fertilization, Kunming, Yunnan Province in June $\left(18.5-27.8{ }^{\circ} \mathrm{C}, 50-183.2 \mathrm{~mm}\right)$-Soil 1 and November (10.5-17.9 $\left.{ }^{\circ} \mathrm{C}, 0.1-6.4 \mathrm{~mm}\right)$-Soil 2 respectively. To minimize spatial heterogeneity, soils were sampled from 10 random sites in the field. After thorough homogenization and removal of visible debris (e.g. roots, stones), soil samples were packed in zip-lock bags and transported to the laboratory with dry ice. The composite soils were sieved through a 2-mm mesh and divided into three parts. One part of the soils was used for physico-chemical analyses (i.e. water content; $\mathrm{pH}$ value; content of total C, N, H, S and O; content of total $\mathrm{Cu}, \mathrm{Zn}, \mathrm{K}, \mathrm{Fe}, \mathrm{Ca}, \mathrm{Cd}$ ). The second part was used to extract soil water. Another part was stored at room temperature $\left(20 \pm 2{ }^{\circ} \mathrm{C}\right)$ for subsequent exposure testing. Total content of C, N, H, S and $\mathrm{O}$ was determined by an elemental analyzer (Vario Micro Cube, Elementar, Germany). A microwave digestion method (MD20H, APL, China) was used in the analysis of soil samples: $0.1 \mathrm{~g}$ of soil was mixed with $5 \mathrm{~mL} \mathrm{HNO}_{3}, 2 \mathrm{~mL} \mathrm{H}_{2} \mathrm{O}_{2}$ and $1 \mathrm{~mL} \mathrm{HF}$ for 20 min pre-digestion at $150{ }^{\circ} \mathrm{C} ; 5 \mathrm{~min}$ digestion at $120^{\circ} \mathrm{C} ; 5$ min digestion at $140{ }^{\circ} \mathrm{C} ; 6$ min digestion at $160^{\circ} \mathrm{C}$; and 30 min digestion at $180^{\circ} \mathrm{C}$. After filtration with $0.45 \mu \mathrm{m}$ strainer, the total content of $\mathrm{Ca}, \mathrm{Cu}, \mathrm{Zn}, \mathrm{Fe}$, $\mathrm{Cr}, \mathrm{Pb}, \mathrm{Cd}$ and $\mathrm{As}$ was determined using the NexION 350 inductively coupled plasma mass spectrometer (ICP-MS, PerkinElmer, USA).

\subsection{Soil microcosm and experimental design}

Each microcosm consisted of $150 \mathrm{~g}$ of soil in a $250 \mathrm{~mL}$ beaker. The nominal exposure doses of CuO NPs $\left(0,250,500\right.$, and $1000 \mathrm{mg} \mathrm{kg}^{-1}$ soil) and ZnO NPs (0, 250, 500, and $1000 \mathrm{mg} \mathrm{kg}^{-1}$ soil) were chosen based on previous studies (Ge et al., 2012; Shah et al., 2014; Xu et al., 2015). Nominal concentrations of CuO NPs and ZnO NPs mixtures were set up as $250 \mathrm{mg} \mathrm{kg}^{-1}$ soil $\times 250 \mathrm{mg} \mathrm{kg}^{-1}$ soil, and $500 \mathrm{mg} \mathrm{kg}^{-1}$ soil $\times 500 \mathrm{mg} \mathrm{kg}^{-1}$ soil. The actual concentrations of $\mathrm{Cu}$ and $\mathrm{Zn}$ after the addition of CuO NPs and ZnO NPs were analyzed by ICP-MS and used for further comparison or correlation analysis. CuO NPs, ZnO NPs and their mixtures were evenly added in each microcosm, incubated at room temperature for $14 \mathrm{~d}$, and covered by foil with small holes to keep unwanted matters away. Soil water content was maintained by weighing the bottles every 4 days and adding ultrapure water $(\mathrm{pH}=$ 
6.68) to supplement any lost water. Two replicates were used for each treatment referring to the study of Asadishad et al. (2018).

\subsection{Quantification of dissolution and dispersion in soil water extract}

To determine the behavior of CuO NPs and ZnO NPs in the soils, $\mathrm{CuO}$ NPs and ZnO NPs were suspended in soil water extract to simulate the dissolution and dispersion processes in microbial assays. To obtain soil water extract, $1 \mathrm{~g}$ of soil was placed into $50 \mathrm{~mL}$ of ultrapure water over night and then centrifuged at $3500 \mathrm{~g}$ for $20 \mathrm{~min}$. The supernatant after centrifugation was then filtered through a $0.45 \mu \mathrm{m}$ strainer and was considered as the soil water extract. CuO NPs and ZnO NPs were added into the soil water extract according to the exposure doses given above. The amount of soil water extract in the mixture was calculated based on the measured soil water content, i.e. water content in $150 \mathrm{~g}$ soil. Size distribution and zeta-potential of suspensions were analyzed by a Zeta PALS instrument (Brook Haven, USA) at $1 \mathrm{~d}$ and $14 \mathrm{~d}$. The solution $\mathrm{pH}$ value was measured by a pH meter (EW-55500-18, Cole-Parmer, USA) at $1 \mathrm{~d}$ and $14 \mathrm{~d}$. After centrifugation at $3500 \mathrm{~g}$ for $20 \mathrm{~min}$, contents of $\mathrm{Cu}$ and $\mathrm{Zn}$ in the supernatant were measured using flame atomic absorption spectroscopy with a Z-2000 (FAAS, Hitachi, Japan).

Different fractions of $\mathrm{Cu}$ and $\mathrm{Zn}$ were also extracted from each treatment with Soil 2 and quantified for comparison. The water soluble fractions of $\mathrm{Cu}$ and $\mathrm{Zn}$ (Jośko et al., 2019) were extracted by mixing $1 \mathrm{~g}$ of soil particles and $10 \mathrm{~mL}$ of ultrapure water, followed by stirring for $24 \mathrm{~h}$. The exchangeable fractions (including water soluble fractions) were measured by mixing $0.35 \mathrm{~g}$ of soil particles and $3.5 \mathrm{~mL}$ of $0.01 \mathrm{M}$ $\mathrm{CaCl}_{2}$. The bioavailable fractions were quantified through the extraction of $2 \mathrm{~g}$ soil by $4 \mathrm{~mL}$ mixed extractant $\left(0.01 \mathrm{M} \mathrm{CaCl}_{2}, 0.005 \mathrm{M}\right.$ diethylenetriaminepentaacetic acid and $0.1 \mathrm{M}$ triethanolamine, $\mathrm{pH}=$ 7.6) (Gao et al., 2018). During each extraction, the mixture was horizontally placed in a shaker at $180 \mathrm{r} / \mathrm{min}$ for $2 \mathrm{~h}$. After centrifugation at $3500 \mathrm{~g}$ for $20 \mathrm{~min}$, the supernatant was filtered through a $0.45 \mu \mathrm{m}$ strainer and acidified with $\mathrm{HNO}_{3}(2 \% v / v)$ for analyzing $\mathrm{Cu}$ and $\mathrm{Zn}$ by the ICP-MS (PerkinElmer, USA).

\subsection{DNA extraction, sequencing, and microbial community analysis}

Soil DNA was extracted from $0.25 \mathrm{~g}$ of soil using a Powersoil DNA isolation kit (MoBio Laboratories, Solana Beach, USA). The concentration and quality of the extracted DNA was then quantified using the NanoDrop NC-2000 (Thermo Fisher Scientific, USA) and the 1.2\% agarose gel electrophoresis method (120 V, $20 \mathrm{~min}$ ) respectively. Because high-throughput sequencing allows the examination of the responses of hundreds of individual taxa simultaneously, Illumina MiSeq-PE250/300 platform for 16S rRNA gene and ITS rRNA gene based amplicon sequencing $(2 \times 300$ base pair) were thus performed at Personal Biotechnology Company (Shanghai, China). Polymerase Chain Reaction (PCR) targeting the $16 \mathrm{~S}$ rRNA gene (V3-V4) was done using bacterial primers, 338F, 5'-ACTCCT ACGGGAGGCAGCA-3', and 806R, 5'-GGACTACHVGGGTWTCTAAT-3'. PCR targeting the ITS rRNA gene (ITS-1) was done using fungal primers, ITS5F (5'-GGAAGTAAAAGTCGTAACAAGG-3') and ITS1R (5'-GCTGCGTTC TTCATCGATGC-3'). The final volume of the reaction mixtures was $25 \mu \mathrm{L}$, including $8.75 \mu \mathrm{L}$ of ultrapure water, $5 \mu \mathrm{L}$ of $5 \times \mathrm{Q} 5$ Buffer, $5 \mu \mathrm{L}$ of $5 \times \mathrm{GC}$ Enhancer, $2 \mu \mathrm{L}$ of dNTP $(2.5 \mathrm{mM}), 2 \mu \mathrm{L}$ of template DNA $(2 \mathrm{ng} / \mu \mathrm{L}), 1 \mu \mathrm{L}$ of each forward and reverse primer $(10 \mu \mathrm{M}), 0.25 \mu \mathrm{L}$ of Q5 High-Fidelity DNA Polymerase (New England Biolabs, USA). The thermal-cycling conditions were as follows: an initial denaturation at $98^{\circ} \mathrm{C}$ for $2 \mathrm{~min}, 25$ cycles of denaturation at $98^{\circ} \mathrm{C}$ for $15 \mathrm{~s}$, annealing at $55^{\circ} \mathrm{C}$ for $30 \mathrm{~s}$ and extension at $72{ }^{\circ} \mathrm{C}$ for $30 \mathrm{~s}$, and a final extension at $72{ }^{\circ} \mathrm{C}$ for $5 \mathrm{~min}$. After size and quality verification by $2 \%$ agarose-gel electrophoresis, PCR products were purified using the Axygen Axy Prep DNA Gel Extraction Kit (Axygen, USA) and quantified using the Quant-iT PicoGreen dsDNA Assay Kit (Invitrogen, USA). Two replicates were sequenced for the treatments with or without MNPs for $1 \mathrm{~d}$ and $14 \mathrm{~d}$.
Sequence processing for MiSeq data analysis was done using the Quantitative Insights Into Microbial Ecology pipeline v 1.8.0 (QIIME, http://qiime.org/). After chimera detection, the remaining high-quality sequences were clustered into operational taxonomic units (OTUs) at a 97\% identity threshold using the UCLUST method (Edgar, 2010). The number of sequences clustered into the same OTU was counted as the abundance assigned to a specific OTU. A representative sequence was chosen from each OTU by selecting the longest one that was most similar to other sequences in the OTU (Ge et al., 2012). The OTUs $<0.001 \%$ relative abundance were eliminated to remove low-quality sequences (Bokulich et al., 2013). The resulting sample-OTU matrix was used for OTU-based community analysis. Taxonomy was assigned to each representative sequence through QIIME against the Silva database (Release 115, https://www.arb-silva.de) for bacteria (Quast et al., 2013) and the UNITF database (Release 5.0, https://unite.ut.ee/) for fungus (Kõljalg et al., 2013).

\subsection{Statistical analysis}

Abundance at levels of phylum, class, order, family and genus present at $>0.5 \%$ abundance was used in the statistical analysis. Fisher's exact test was performed to assess the differences in the bacterial or fungal richness, and in the Alpha diversity index (i.e. Chao1 richness estimator, Abundance-based Coverage Estimator (ACE) metric, Shannon diversity index) among the different treatments. The Chao 1 and ACE estimators were selected based on community richness (Gotelli and Colwell, 2011), while the Shannon index was selected to consider the evenness of the community as well (Allen et al., 2009). To test how the microbial communities systematically changed with the increasing addition of MNPs, the Person correlation coefficient and the statistical significance were calculated to judge the correlation between community dissimilarities (e.g. species, alpha diversity index) and the concentrations of $\mathrm{CuO}$ NPs and ZnO NPs (i.e. actual concentrations of $\mathrm{Cu}$ and $\mathrm{Zn}$ after the addition of MNPs in the soil, water soluble species of $\mathrm{Cu}$ or $\mathrm{Zn}$, water soluble and some exchangeable species of $\mathrm{Cu}$ or $\mathrm{Zn}$, bioavailable species of $\mathrm{Cu}$ and $\mathrm{Zn}$, particulate forms of $\mathrm{Cu}$ or $\mathrm{Zn}$ in the soil, and simulated water soluble species of $\mathrm{Cu}$ or $\mathrm{Zn}$ in soil water extract). Analysis of similarities (ANOSIM) was used to test the difference between bacterial and fungal communities exposed to $\mathrm{CuO}$ NPs and $\mathrm{ZnO}$ NPs at diverse levels. A value of $<0.05$ indicates a significant difference between the compared values. To test the changes of metabolic function of sensitive bacteria, phylogenetic investigation of communities by reconstruction of unobserved states (PICRUSt, http://huttenhower.sph.harvard.edu/ galaxy/tool_runner?tool_id=PICRUSt_normalize) was conducted (Langille et al., 2013) to annotate 16S rRNA genes based on the KEGG database (http://www.genome).

The independent action approach on the basis of additivity was used to predict the sum of individual effects (Liu et al., 2017). All these analyses were performed using the Origin 8.0 software (Origin Lab, USA).

$E\left(c_{\text {mix }}\right)=1-\prod_{i=1}^{n}\left(1-E\left(c_{i}\right)\right)$

Where $c_{i}$ is the concentration of the $i$ th component in the mixture; $E$ $\left(c_{\text {mix }}\right)$ is the total effect on the test organism caused by the mixture; $E$ $\left(c_{\mathrm{i}}\right)$ is the toxic effect on the test organism caused by the $i$ th component in the mixture.

\section{Results and discussion}

\subsection{Properties of soil, CuO NPs and ZnO NPS}

As shown in Table $\mathrm{S} 1$, Soil 1 was mildly alkaline $(\mathrm{pH}=7.24)$ with $25.3 \%$ water content, while Soil 2 containing $22.1 \%$ water was weakly acid $(\mathrm{pH}=5.70)$. The $\mathrm{C}$ and $\mathrm{N}$ contents of Soil 2 were more than 
twice the values of the $\mathrm{C}$ and $\mathrm{N}$ contents of Soil 1. The TEM images (Fig. 1) revealed that the CuO NPs and ZnO NPs were spherical and semi-spherical agglomerates respectively before the application in soil. The aggregation appeared to increase in the mixture treatment.

Dissolution and dispersion are important processes determining the bioavailability of MNPs. The surface charges of CuO NPs at different concentrations were all negative in soil extract after 1d and 14d, while the surface charges of the $\mathrm{ZnO}$ NPs and the mixtures of $\mathrm{CuO}$ and $\mathrm{ZnO}$ NPs were all positive at various concentrations (Fig. S1). The solution $\mathrm{pH}$ $(\approx 7.6-8.37)$ below the zero point of charge for ZnO NPs $(\approx 9.0$ or 9.3 , Wang et al., 2016) resulted in surface protonation and the positive charges of ZnO NPs. In addition, the hydrodynamic diameters of the $\mathrm{CuO}$ NPs increased significantly with increasing concentrations and exposure duration (Fig. S1). The increased contact possibilities among particles and reduced repulsion between particles at higher concentrations may have promoted aggregation (Holsapple et al., 2005).

Low concentrations of $\mathrm{Cu}$ and $\mathrm{Zn}$ accounting for less than $1.5 \%$ of the applied particles were detected both in the water soluble fractions of the soil and in the soil water extract (Fig. S2), indicating the low solubility of $\mathrm{CuO}$ and ZnO NPs (Adeleye et al., 2014) at the investigated soilrelated water chemistry conditions. Rapid dissolution also occurred since little difference was observed between $1 \mathrm{~d}$ and $14 \mathrm{~d}$ data of the water soluble fractions of CuO NPs, ZnO NPs and their mixtures. The exchangeable and bioavailable fractions of $\mathrm{Cu}$ and $\mathrm{Zn}$ in the soil increased over time (Fig. S2), implying that MNPs in the soil dissolved slowly over time in the presence of acids, salts, organic matter, and/or microorganisms.

\subsection{Positive effects of CuO NPs and ZnO NPs on microbial richness and diversity}

The comparison of the extracted bacterial and fungal groups between the control and MNPs-applied soil illustrated that $\mathrm{CuO}$ and $\mathrm{ZnO}$ NPs increased the microbial community richness (Fig. 2). At higher doses of ZnO NPs (> $250 \mathrm{mg} \mathrm{kg}^{-1}$ soil, i.e. $162.73 \mathrm{mg} \mathrm{kg}^{-1}$ soil of Zn), the stimulatory effects became weaker. Our first hypothesis concerning soil microbial community richness was thus verified, and the impacts of MNPs on microbial community diversity will be discussed as follows. Released ions of MNPs (i.e. $\mathrm{Cu}$ and $\mathrm{Zn}$ ) are essential for physiological processes, and can be absorbed by microbes to supplement potential nutritional deficiency in the red soil (Wyszkowska et al., 2013). Cu is always a co-factor for numerous enzymes; $\mathrm{Zn}$ participates in the formation of an enzyme-substrate system, protein translation, gene copying and multiplication of a genetic chain (Sekler et al., 2007). At elevated concentrations, $\mathrm{Cu}$ or $\mathrm{Zn}$ becomes toxic to microorganisms. For example, $\mathrm{Cu}$ (200-400 $\mathrm{mg} \mathrm{Cu} \mathrm{kg}^{-1}$ ) inhibited the growth of basidiomycetous and ascomycetous fungi in the ABTS plate tests (Hartikainen et al., 2012). Xu et al. (2015) explained that the negative effects may be most likely due to more bioavailable CuO NPs to microbes in flooded paddy soil, as determined by the increased Cu contents in the soil extractions and in the microbial cells.

To further study the dose-dependent manner, different metal fractions were analyzed and their importance in dominating biological effects of MNPs on soil microbes were evaluated. For bacteria, the extracted community groups increased significantly $(p<0.05)$ with the water soluble, bioavailable, or particulate forms of $\mathrm{CuO}$ NPs (Table S3), which to some extent coincided with previous results for plants (Liu et al., 2016) and for bacterial community (Ge et al., 2013). The simulated water soluble form of ZnO NPs also largely explained $(r=0.86, p=0.003$, Table S3) the increased richness of overall bacterial community in the red soil. This was in agreement with previously reported results for one soil bacterium (Heinlaan et al., 2008) and a microbial community (Xu et al., 2015). For fungi, the number of extracted community groups was significantly increased by the simulated water soluble concentration of ZnO NPs, but not by the different fractions of $\mathrm{CuO}$ NPs. The above results verified our second hypothesis that dissolved and particulate forms can be used to explain the impacts of MNPs on microbial community richness, which depending on the MNPs types. Different individual taxa have different tolerance and sensitivity to different metals (discussed in Section 3.3), the sum of which appears to be the observed community richness. Fungal cells $(1-100 \mu \mathrm{m})$ (Alexopoulos and Alexopoulos and Mims, 1979) with
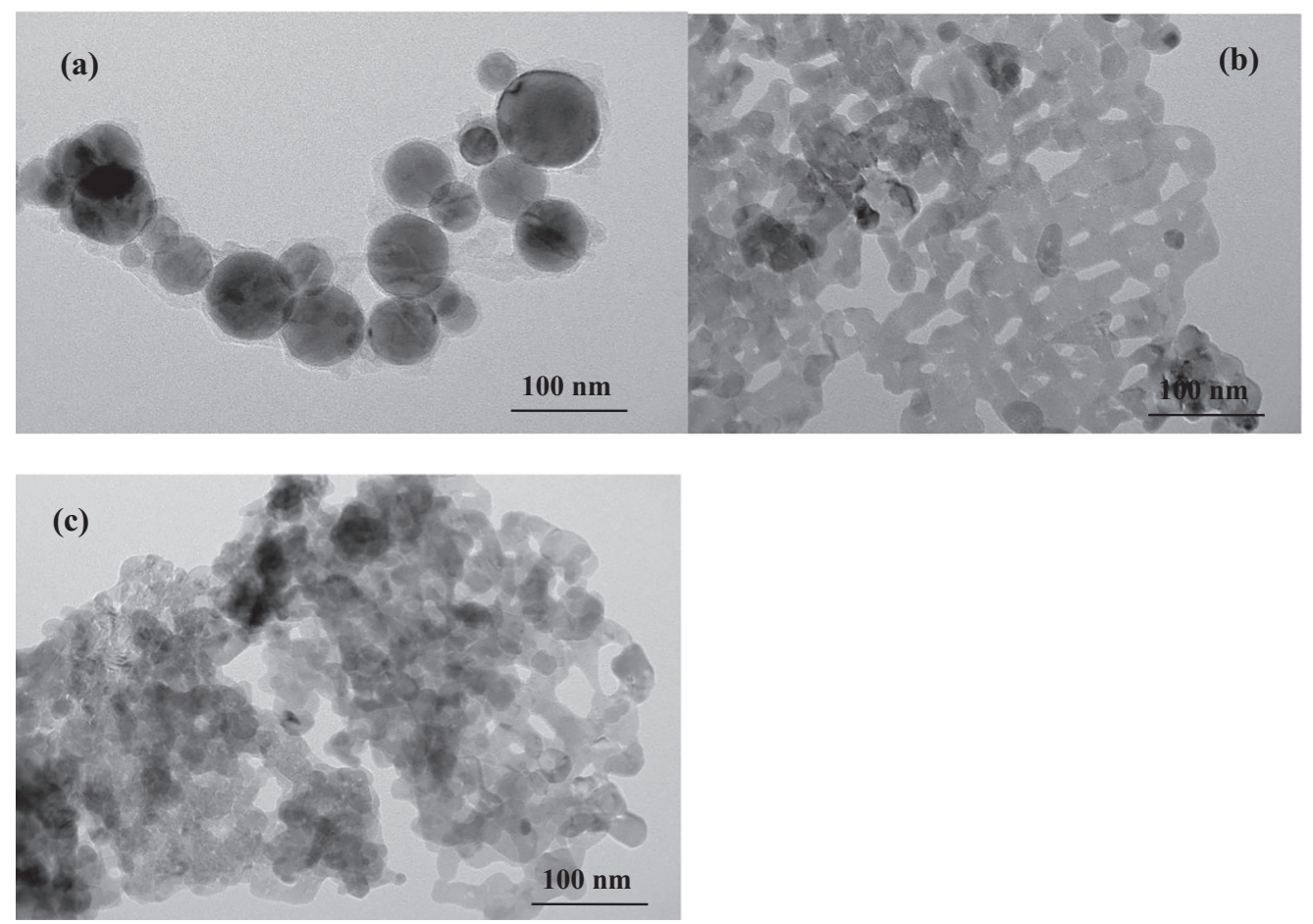

Fig. 1. The TEM images of CuO NPs (a), ZnO NPs (b), and their mixtures (c) before the application in soil. Scale bars indicate size (nm). 

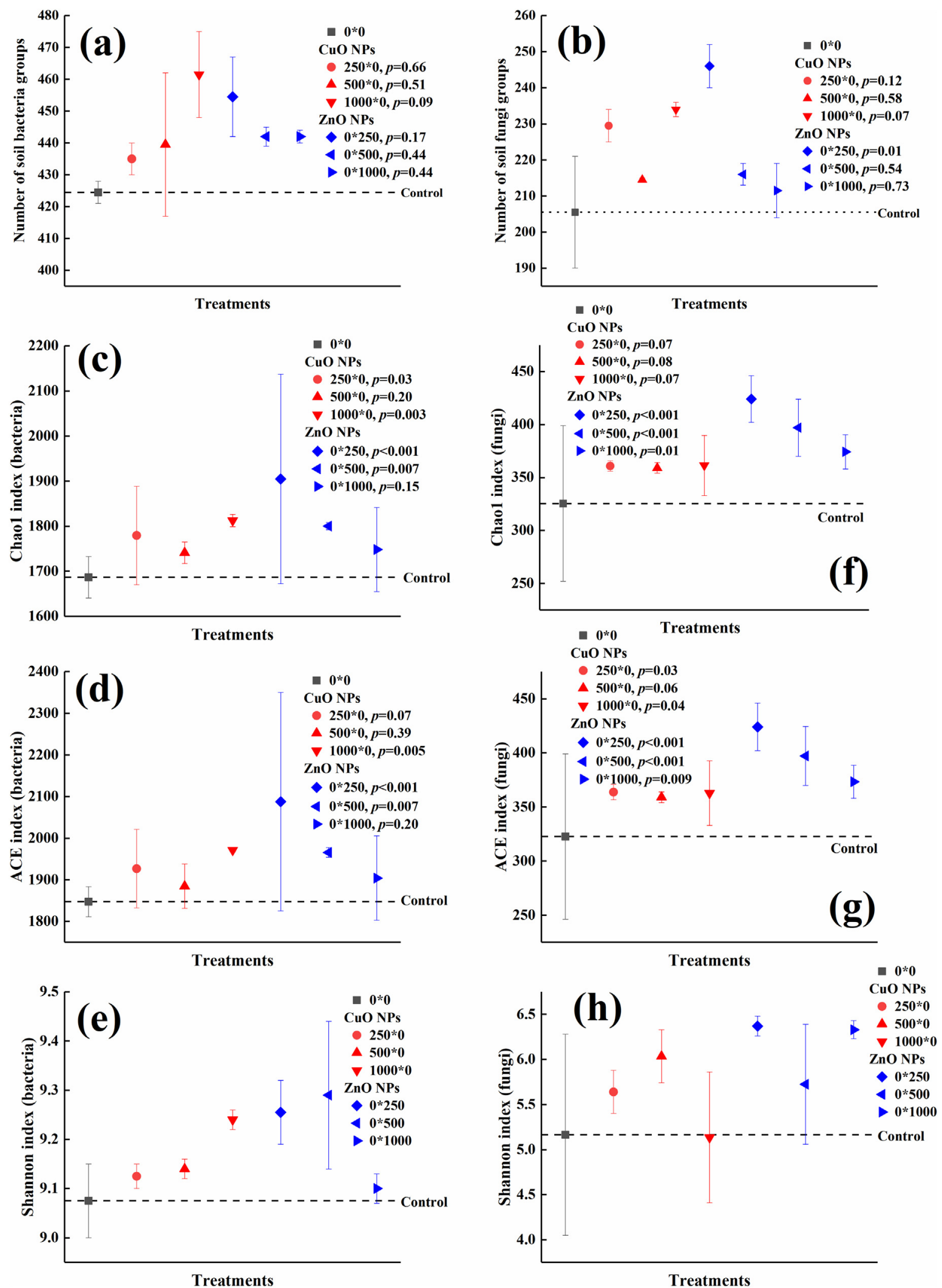

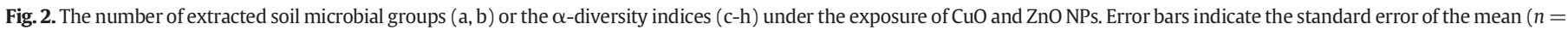

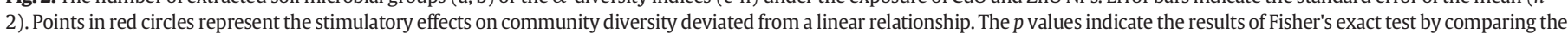
treatments with the control groups. 

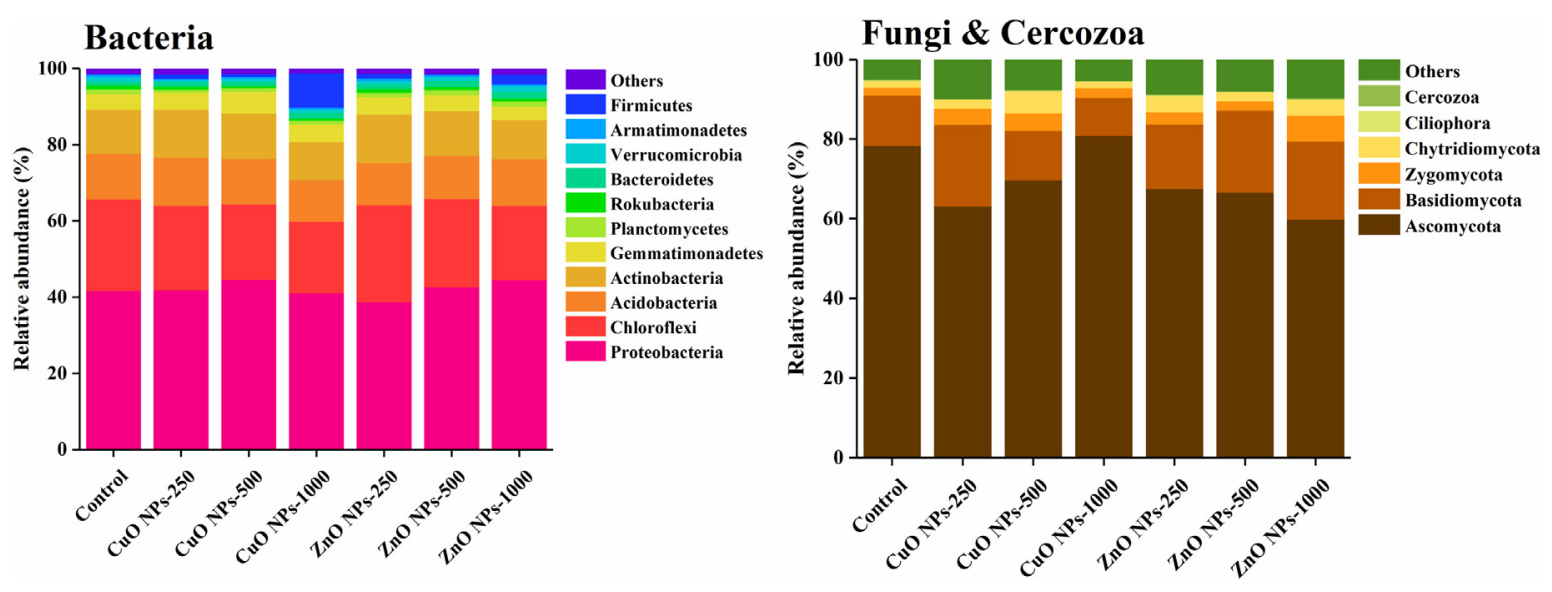

Fig. 3. Relative abundance of the microbial phyla sequences at different treatments (relative abundance $>0.5 \%$ ).

their complex structure are normally larger than bacterial cells (0.5- $5 \mu \mathrm{m})$ (Wang and Wang and Hong, 2015), which enabled their tolerance to MNPs. In addition, CuO NPs showed more obvious impact on bacteria community than ZnO NPs according to the above findings and ANOSIM results $(R=0.42, p=0.01)$. Although the total content of $\mathrm{Cu}$ in the background red soil was 10 times that of Zn (see Table S2), the bioavailable fractions of $\mathrm{Cu}$ in soil $\left(1.37 \mathrm{mg} \mathrm{kg}^{-1}\right.$ soil) was only less than twice that of $\mathrm{Zn}$ without the addition of MNPs $\left(0.75 \mathrm{mg} \mathrm{kg} \mathrm{kg}^{-1}\right.$ soil). The bacteria present may have evolved to utilize $\mathrm{Cu}$ more effectively than Zn (Shah et al., 2014). The added CuO NPs will further increase the bioavailable fractions of $\mathrm{Cu}$ in soil and meet the requirement of these bacteria (Raliya and Tarafdar, 2013), thus increasing the community richness. Thereupon, the metal fractions of MNPs in dominating their biological impacts depended on both the MNPs types and the microbial community of action.

The most widely used $\alpha$-diversity indices, including Chao1, ACE, and Shannon indices, were calculated to estimate the alterations of withinhabitat diversity in the presence or absence of MNPs. As shown in Fig. 2, the values of $\alpha$-diversity indices for bacteria and fungi in most of the treatments with MNPs were larger than that of the control groups. The Shannon Index for bacteria increased linearly in response to increasing concentrations of CuO NPs (see Table S4). Thus, not only the bacterial community richness but also the community diversity was positively related to the relatively low amount of $\mathrm{CuO}$ NPs added in the soil. At higher doses of $\mathrm{CuO}$ and $\mathrm{ZnO}$ NPs, the stimulatory effects on community diversity deviated from a linear relationship (see points in red circles). Considering the promotional effects of $\mathrm{CuO}$ NPs and $\mathrm{ZnO}$ NPs on soil microbial community diversity at low dosage, the first and second hypotheses were thus further verified. $\mathrm{CuO}$ and $\mathrm{ZnO}$ NPs as micro-nutrients promoted the soil microbial community richness and diversity, while their positive effects were impaired at very high concentrations ( $>500 \mathrm{mg} \mathrm{kg}^{-1}$ soil, i.e. $347.58 \mathrm{mg} \mathrm{kg}^{-1}$ soil of $\mathrm{Cu}$ and $321.73 \mathrm{mg} \mathrm{kg}^{-1}$ soil of $\mathrm{Zn}$ ).

\subsection{Structure of the soil microbial community as affected by CuO NPs and $\mathrm{ZnO}$ NPS}

Generally, the relative abundance of the microbial phyla sequences varied for different treatments of CuO NPs and ZnO NPs (Fig. 3). Proteobacteria (38.73\% 44.61\%) and Ascomycota (59.88\% 80.94\%) were the dominant bacterial and fungal phyla with the highest relative abundance among the treatments. The dominance of Ascomycota

Table 1

The correlation analysis results between relative abundance of bacterial or fungal susceptible taxa at different taxonomic levels and exposure doses of CuO NPs or ZnO NPs in Soil 2.

\begin{tabular}{|c|c|c|c|c|c|c|c|c|c|}
\hline & & \multicolumn{4}{|l|}{ The CuO NPs exposure } & \multicolumn{4}{|l|}{ The ZnO NPs exposure } \\
\hline & & Name & Relation & $r$ & $p$ & Name & Relation & $r$ & $p$ \\
\hline \multirow[t]{12}{*}{ Bacteria } & Phylum & Chloroflexi & - & 0.951 & 0.049 & Armatimonadetes & - & 0.99 & 0.010 \\
\hline & Class & n.s. & & & & $A D 3$ & - & 0.945 & 0.049 \\
\hline & & & & & & Anaerolineae & - & 0.957 & 0.043 \\
\hline & Order & IMCC26256 & - & 0.942 & 0.049 & Sphingomonadales & + & 0.989 & 0.011 \\
\hline & & & & & & SBR1031 & - & 0.943 & 0.049 \\
\hline & & & & & & Solirubrobacterales & - & 0.977 & 0.023 \\
\hline & & & & & & Catenulisporales & - & 0.942 & 0.049 \\
\hline & Family & Acidobacteriaceae & - & 0.950 & 0.049 & Sphingomonadaceae & + & 0.989 & 0.011 \\
\hline & & Polyangiaceae & - & 0.975 & 0.025 & Acidothermaceae & - & 0.973 & 0.027 \\
\hline & Genus & Bradyrhizobium & + & 0.959 & 0.041 & Sphingomonas & + & 0.973 & 0.027 \\
\hline & & Pajaroellobacter & - & 0.979 & 0.021 & Mesorhizobium & + & 0.994 & 0.006 \\
\hline & & & & & & Acidothermus & - & 0.973 & 0.027 \\
\hline \multirow[t]{7}{*}{ Fungi } & Phylum & n.s. & & & & n.s. & & & \\
\hline & Class & Archaeorhizomycetes & - & 0.943 & 0.049 & n.s. & & & \\
\hline & & Pucciniomycetes & - & 0.980 & 0.020 & & & & \\
\hline & Order & Archaeorhizomycetales & - & 0.943 & 0.049 & n.s. & & & \\
\hline & & Pleosporales & + & 0.977 & 0.023 & & & & \\
\hline & Family & Archaeorhizomycetaceae & - & 0.943 & 0.049 & n.s. & & & \\
\hline & Genus & Archaeorhizomyces & - & 0.943 & 0.049 & Penicillium & + & 0.983 & 0.017 \\
\hline Others & Phylum & n.s. & & & & Cercozoa & + & 0.975 & 0.025 \\
\hline
\end{tabular}

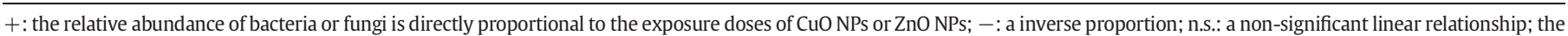

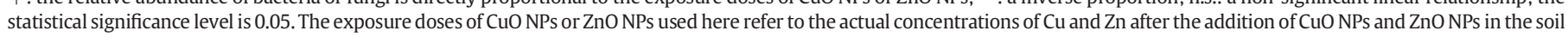
which were analyzed by ICP-MS. 
indicated that the sample soil was similar to arid or semiarid temperate grasslands (Chen et al., 2017).

The relative abundances of most taxa were not significantly influenced by MNPs. The sensitive taxonomic groups with higher abundance in the community (Ge et al., 2012) may be the explanation for the promotion of MNPs on soil microbial community richness and diversity. The bacteria or fungi were thus regarded as susceptible taxa and summarized in Table 1 if a significant correlation occurred between relative abundance $(>0.5 \%$ ) of the microbial phylum/class/order/family/genus sequences and concentrations of $\mathrm{CuO}$ NPs or ZnO NPs. For bacteria, the relative abundance of Sphingomonadales (4.84\% to 5.61\%) were significantly $(p<0.05)$ enriched with increasing concentrations of ZnO NPs, while the relative abundance of SBR 1031 (0.68\% to $0.80 \%)$, Solirubrobacterales ( $0.63 \%$ to $0.87 \%$ ), Catenulisporales ( $0.38 \%$ to $0.61 \%$ ) were reduced after $\mathrm{ZnO}$ NPs application. For fungi, a positive correlation was observed for the order Pleosporales (1.08\% to 6.39\%), while a negative correlation occurred for the order Archaeorhizomycetales $(0.17 \%$ to $0.67 \%$ ) and $\mathrm{CuO}$ NPs application. Similarly, for eukaryotes, the relative abundance of Cercozoa (a diverse clade lacking distinctive morphological or behavioral characters) (Adl et al., 2012) was also directly proportional to the exposure doses of ZnO NPs. These findings provided further evidences for the structure of microbial community shifted under the exposure of $\mathrm{CuO}$ NPs and ZnO NPs. Moreover, under the ZnO NPs exposure, the relative abundance of Armatimonadetes significantly decreased across the exposure doses, which was not observed for CuO NPs and fungal phyla sequences. Thus, the sensitivity of a microbial community to MNPs also depended on the type or composition of particles. The relative abundance of most susceptible taxa decreased with increasing concentrations of CuO NPs, while the Shannon index was proportional to the exposure concentration (Fig. 2). The Shannon index seemed to be more sensitive to community richness and rare OTUs according to its algorithm (Tuomisto, 2010). For example, the phyla Epsilonbacteraeota, Fibrobacteres, Chlamydiae and Deferribacteres were newly emerging after the addition of $\mathrm{CuO}$ NPs, the relative abundance of which was less than $0.5 \%$ and they were not included in Table 1.

Some of the microbial taxonomic groups related to specific soil biochemical processes were indeed sensitive to the added $\mathrm{CuO}$ NPs or $\mathrm{ZnO}$ NPs. For example, the relative abundance of species associated with the decomposition of recalcitrant organic pollutants (Ge et al., 2012), namely the order Sphingomonadales, the family Sphingomonadaceae and the genus Sphingomonas, increased significantly with the increased addition of ZnO NPs. On the contrary, the family Acidothermaceae and the genus Acidothermus correlated with rapid degradation of cellulose (Berry et al., 2014), and declined in response to ZnO NPs. It was thus hard to identify a particular group that is responsible for specific functions of the soil (e.g. the $\mathrm{N}$ cycle), because some of the ascending taxa (Bradyrhizobium, and Mesorhizobium) and some of the declining taxa (Armatimonadetes and Chloroflexi) which contain ammonia-/nitriteoxidizing bacteria, anammox bacteria, and denitrifying bacteria, are both reported to be involved in nitrogen fixation, nitrogen removal or in the (de)nitrification process (Li, 2017). In other words, stimulatory and inhibitory actions of MNPs against microbial processes can also be advantages to control nitrogen losses and production of greenhouse gases from soils (Achari and Kowshik, 2018; Gilbertson et al., 2020). For fungi, the relative abundance of the class Archaeorhizomycetes, the order Archaeorhizomycetales, the family Archaeorhizomycetaceae, and the genus Archaeorhizomyces decreased significantly at elevated $\mathrm{CuO}$ NPs concentrations. However, there is still no evidence that they can form mycorrhizal with plants or they are plant pathogens. As an ancient class of fungi, species in the Archaeorhizomycetes may exist along a continuum from root endophytic to free-living saprophytic life strategies and no single ecological role can be assigned to the class (Rosling et al., 2013). Furthermore, the relative abundance of Cercozoa was significantly increased after the addition of ZnO NPs (Table 1). The regulating control of ZnO NPs on soil ecosystem was again illustrated because the diversity of protozoan (as bacterial grazers) plays a very important role in the soil food web (Harder et al., 2016).

\subsection{Environmental influence factors}

The impacts of the co-existence of $\mathrm{CuO}$ and $\mathrm{ZnO}$ NPs were investigated for their potential joint application as micronutrient fertilizers (Achari and Kowshik, 2018). For soil bacteria, the mixture treatment of $\mathrm{CuO}$ and $\mathrm{ZnO}$ NPs showed decreased group numbers as compared with the sum of individual treatments (Fig. 4a), while for fungi, the mixture increased the group numbers (Fig. $4 \mathrm{~b}$ ). The significance testing results indicated that the measured values of mixture treatments did not deviate significantly from the predicted values on the basis of additivity except for fungi treated with $250^{*} 250$. This finding was not consistent with our previous study (Liu et al., 2016) that interactions were not observed between $\mathrm{CuO}$ and $\mathrm{ZnO}$ NPs applied in soil. The heteroaggregation of $\mathrm{CuO}$ (negatively charged) and ZnO NPs (positively charged) may decrease the exposed surface area and the ion release of MNPs, which consequently restricted the mobility or the opportunities of MNPs for contact and interaction.

As a comparison, the richness and biodiversity of Soil 1 were higher than that of Soil 2 without the addition of MNPs. For instance, the numbers of soil bacterial (690) or fungal (453) groups and the values of ACE
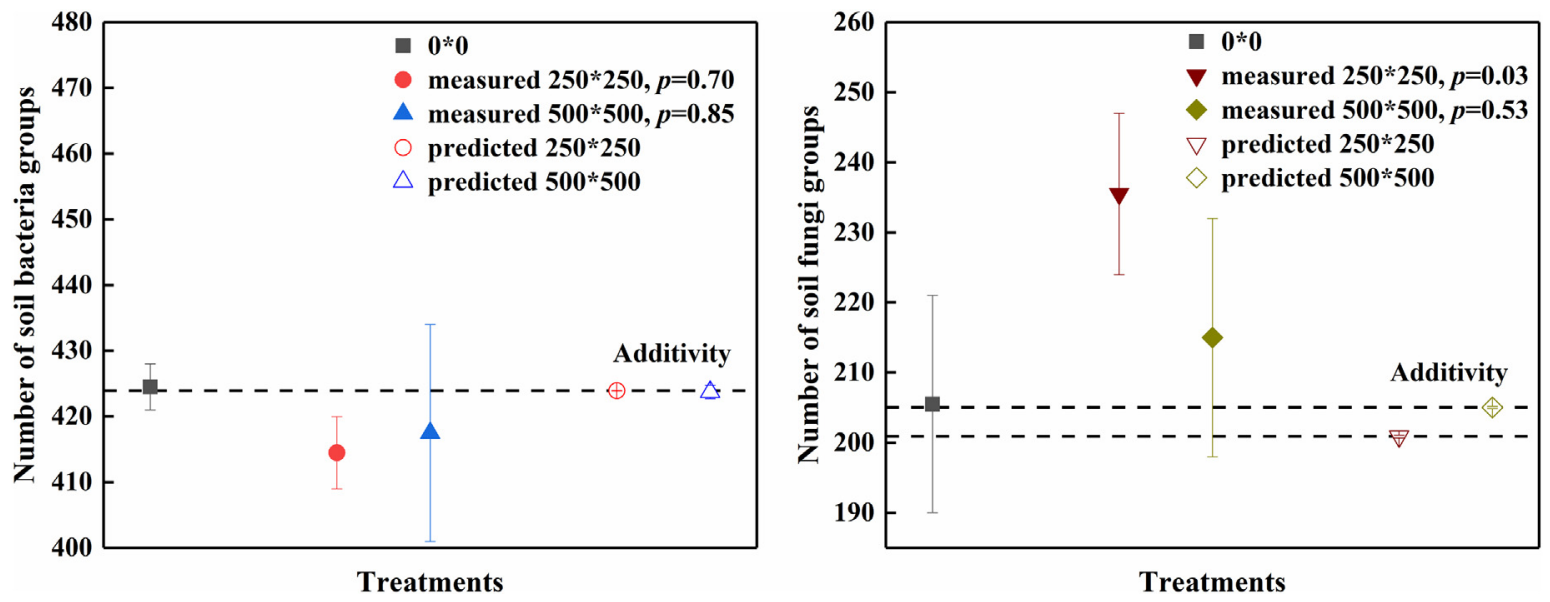

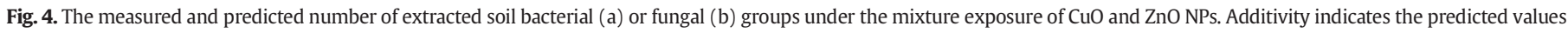

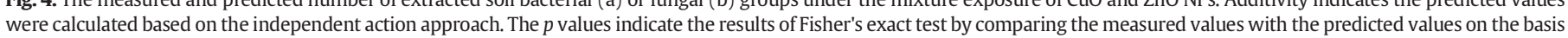
of additivity. Error bars indicate the standard error of the mean $(n=2)$. 
index (8327.14) and Chao 1 index (7898.08) for bacteria in Soil 1 were all found to be higher than that in Soil 2 (see Fig. 2). Relatively more water of a neutral environment (e.g. $\mathrm{pH}=7.24$ ) can be a reason why Soil 1 (see Table S1) was more suitable for microbial growth (Jansson and Jansson and Hofmockel, 2019). The high abundance and diversity of the microbial population in Soil 1 may lead to an increase of the mineralization rate of organic matter (Schmidt et al., 2011), thus leading to the reduced C/N(10.62) as compared with that of Soil 2 (15.38). Similar positive effects on community richness and diversity of soil microorganisms were observed for ZnO NPs in Soil 1, but not for CuO NPs. The added $\mathrm{CuO}$ NPs in Soil 1 decreased the number of bacteria groups (644) and the corresponding ACE (7493.31) or Chao 1 (7045.71) values, while still a stimulant to fungi. Impacts of $\mathrm{CuO}$ NPs on soil microorganisms was thus more easily influenced by environmental factors as compared with ZnO NPs. With a higher content of organic matter, CuO NPs applied in Soil 2 may be covered with organic matters and move to a longer distance, or their released metal ions may be complexed with these substances (Liu et al., 2020), which altered their bioavailability. In addition, the red soil $(\mathrm{pH}<7)$ containing abundant Fe-based particles with positive charges due to protonation (Lei et al., 2018), may easily form heteroaggregates with the negatively charged $\mathrm{CuO}$ NPs rather than the positively charged ZnO NPs (see Fig. S1) by electrostatic interactions. The adsorbed CuO NPs may have a higher possibility to contact or to be up-taken by the bacteria living on the soil particle surfaces. Thus, responses of soil microbes to MNPs can be affected by soil conditions and MNPs types. With the study presented here we only address the impacts of $\mathrm{CuO}$ NPs and ZnO NPs on soil microbial richness and diversity in a red soil without artificial fertilization for the first time. The application of biosolids or the irrigation of sewage water may both increase the content of organic matter in soil and further impact the fate of MNPs. How the MNPs interact with the soil amendments should be further investigated.

\section{Conclusions}

The present study tested two hypotheses to identify the potential application prospect of MNPs for improving soil fertility. As micronutrients, ions released from $\mathrm{CuO}$ and $\mathrm{ZnO}$ NPs promoted not only the soil microbial community richness but also the community diversity in the form of an increased number of soil bacteria or fungi groups and the increased $\alpha$-diversity indices. However the positive effects were impaired at high concentrations (the first hypothesis verified). Both particulate and dissolved forms explained the impacts of $\mathrm{CuO}$ and $\mathrm{ZnO}$ NPs on microbial community, but depending on the MNPs types or the biota types (the second hypothesis verified). As some individual taxa was found to be very sensitive to $\mathrm{CuO}$ and $\mathrm{ZnO}$ NPs, the addition of MNPs did affect the structure of microbial community in the red loam soil. Mixing of $\mathrm{CuO}$ and $\mathrm{ZnO}$ NPs had no additional benefits than the sum of individual effects on the soil bacterial community. In soils with less organic matter, the added $\mathrm{CuO}$ NPs reduced the number of bacteria groups and diversity indices, which was contrary to the effects of ZnO NPs and their mixtures. To summarize, a positive impact of $\mathrm{CuO}$ and $\mathrm{ZnO}$ NPs can be foreseen in agricultural usage, while attention should be paid to the selection of the dose applied and variations in soil properties.

\section{CRediT authorship contribution statement}

Yang Liu: Conceptualization, Methodology, Data curation, Investigation. Yang Li: Writing - original draft, Data curation. Bo Pan: Conceptualization, Writing - review \& editing, Supervision. Xinyue Zhang: Writing - original draft, Data curation. Huang Zhang: Writing - original draft, Data curation. Christian E.W. Steinberg: Writing - review \& editing. Hao Qiu: Writing - review \& editing. Martina G. Vijver: Writing - review \& editing. Willie J.G.M. Peijnenburg: Writing - review \& editing, Data curation.

\section{Declaration of competing interest}

The authors declare that they have no known competing financial interests or personal relationships that could have appeared to influence the work reported in this paper.

\section{Acknowledgement}

This work was supported by the National Natural Scientific Foundation of China (41703111, 41967039); the Yunnan Provincial Ten Thousand Plan (YNWR-QNBJ-2019-065); the Yunnan Basic Research Plan (202001AT070042); and a talent cultivation project at KUST (KKSY201622012).

\section{Appendix A. Supplementary data}

Supplementary data to this article can be found online at https://doi. org/10.1016/j.scitotenv.2020.143807.

\section{References}

Achari, G., Kowshik, M., 2018. Recent developments on nanotechnology in agriculture: plant mineral nutrition, health, and interactions with soil microflora. J. Agric. Food Chem. 66, 8647-8661.

Adeleye, A.S., Conway, J.R., Perez, T., Rutten, P., Keller, A.A., 2014. Influence of extracellular polymeric substances on the long-term fate, dissolution, and speciation of copperbased nanoparticles. Environ. Sci. Technol. 48 (21), 12561-12568.

Adhikari, T., Sarkar, D., Mashayekhi, H., Xing, B., 2016. Growth and enzymatic activity of maize (Zea mays L.) plant: solution culture test for copper dioxide nano particles. J. Plant Nutr. 39 (1), 99-115.

Adl, S.M., Simpson, A.G., Lane, C.E., Lukes, J., Bass, D., Bowser, S.S., Brown, M.W., Burki, F., Dunthorn, M., Hampl, V., Heiss, A., Hoppenrath, M., Lara, E., Le Gall, L., Lynn, D.H., McManus, H., Mitchell, E.A., Mozley-Stanridge, S.E., Parfrey, L.W., Pawlowski, J., Rueckert, S., Shadwick, L., Schoch, C.L., Smirnov, A., Spiegel, F.W., 2012. The revised classification of eukaryotes. J. Eukaryot. Microbiol. 59 (5), 429-493.

Alexopoulos, C.J., Mims, C.W., 1979. Introductory Mycology. John Wiley, New York.

Allen, B., Kon, M., Baryam, Y., 2009. A new phylogenetic diversity measure generalizing the shannon index and its application to phyllostomid bats. Am. Nat. 174 (2), 236-243.

Antisari, L.V., Carbone, S., Gatti, A., Vianello, G., Nannipieri, P., 2013. Toxicity of metal oxide $\left(\mathrm{CeO}_{2}, \mathrm{Fe}_{3} \mathrm{O}_{4}, \mathrm{SnO}_{2}\right)$ engineered nanoparticles on soil microbial biomass and their distribution in soil. Soil Biol. Biochem. 60, 87-94.

Asadishad, B., Chahal, S., Akbari, A., Cianciarelli, V., Azodi, M., Ghoshal, S., Tufenkji, N., 2018. Amendment of agricultural soil with metal nanoparticles: effects on soil enzyme activity and microbial community composition. Environ. Sci. Technol. 52 (4), 1908-1918.

Berry, A.M., Barabote, R.D., Normand, P., 2014. The family Acidothermaceae, in: Rosenberg, E., DeLong, E.F., Lory, S., Stackebrandt, E., Thompson, F. (Eds.), The Prokaryotes. Springer, Berlin, pp.13-19.

Bokulich, N.A., Subramanian, S., Faith, J.J., Gevers, D., Gordon, J.I., Knight, R., Mills, D.A., Caporaso, J.G., 2013. Quality-filtering vastly improves diversity estimates from illumina amplicon sequencing. Nat. Methods 10 (1), 57-59.

Chen, Y.L., Xu, T.L., Veresoglou, S.D., Hu, H.W., Hao, Z.P., Hu, Y.J., Liu, L., Deng, Y., Rilling, M.C., Chen, B.D., 2017. Plant diversity represents the prevalent determinant of soil fungal community structure across temperate grasslands in northern China. Soil Biol. Biochem. 110, 12-21.

Edgar, R.C., 2010. Search and clustering orders of magnitude faster than blast. Bioinformatics 26 (19), 2460.

FAO/WHO [Food and Agriculture Organization of the United Nations/World Health Organization], 2010. FAO/WHO Expert Meeting on the Application of Nanotechnologies in the Food and Agriculture Sectors: Potential Food Safety Implications. Rome: Meeting Report.

Gao, X., Avellan, A., Laughton, S., Vaidya, R., Rodrigues, S.M., Casman, E.A., Lowry, G.V. 2018. CuO nanoparticle dissolution and toxicity to wheat (Triticum aestivum) in rhizosphere soil. Environ. Sci. Technol. 52 (5), 2888-2897.

Ge, Y., Schimel, J.P., Holden, P.A., 2011. Evidence for negative effects of $\mathrm{TiO}_{2}$ and $\mathrm{ZnO}$ nanoparticles on soil bacterial communities. Environ. Sci. Technol. 45, 1659-1664.

Ge, Y., Schimel, J.P., Holden, P.A., 2012. Identification of soil bacteria susceptible to $\mathrm{TiO}_{2}$ and $\mathrm{ZnO}$ nanoparticles. Appl. Environ. Microbiol. 78 (18), 6749-6758.

Ge, Y., Priester, J.H., Van De Werfhorst, L.C., Schimel, J.P., Holden, P.A., 2013. Potential mechanisms and environmental controls of $\mathrm{TiO}_{2}$ nanoparticle effects on soil bacterial communities. Environ. Sci. Technol. 47, 14411-14417.

Gilbertson, L.M., Pourzahedi, L., Laughton, S., Gao, X., Zimmerman, J.B., Theis, T.L., Westerhoff, P., Lowry, G.V., 2020. Guiding the design space for nanotechnology to advance sustainable crop production. Nat. Nanotechnol. 15, 801-810. https://doi.org/ 10.1038/s41565-020-0706-5.

Gotelli, N.J., Colwell, R.K., 2011. Estimating species richness, in: Magurran, A.E., McGill, B.J. (Eds.), Biological Diversity. Frontiers in Measurement and Assessment. Oxford University Press, Oxford, pp. 39-54. 
Harder, C.B., Rønn, R., Brejnrod, A., Bass, D., Al-Soud, W.A., Ekelund, F., 2016. Local diversity of heathland Cercozoa explored by in-depth sequencing. ISME J 10 (10), 2488-2497.

Hartikainen, S., Lankinen, P., Rajasärkkä, J., Hilkka, K., Virta, M., Hatakka, A., Kähkönen, M., 2012. Impact of copper and zinc on the growth of saprotrophic fungi and the production of extracellular enzymes. Boreal Environ. Res. 17, 210-218.

Heinlaan, M., Ivask, A., Blinova, I., Dubourguier, H.C., Kahru, A., 2008. Toxicity of nanosized and bulk $\mathrm{ZnO}, \mathrm{CuO}$ and $\mathrm{TiO}_{2}$ to bacteria Vibrio fischeri and crustaceans Daphnia magna and Thamnocephalus platyurus. Chemosphere 71, 1308-1316.

Holsapple, M.P., Farland, W.H., Landry, T.D., MonteiroRiviere, N.A., Carter, J.M., Walker, N.J., Thomas, K.V., 2005. Research strategies for safety evaluation of nanomaterials, part II: toxicological and safety evaluation of nanomaterials, current challenges and data needs. Toxicol. Sci. 88 (1), 12-17.

Huang, S., Wang, L., Liu, L., Hou, Y., Li, L., 2015. Nanotechnology in agriculture, livestock, and aquaculture in China. A review. Agron. Sustain. Dev. 35, 369-400.

Jansson, J.K., Hofmockel, K.S., 2019. Soil microbiomes and climate change. Nat. Rev. Microbiol. 18, 35-46.

Jośko, I., Oleszczuk, P., Dobrzyńska, J., Futa, B., Joniec, J., Dobrowolski, R., 2019. Long-term effect of $\mathrm{ZnO}$ and $\mathrm{CuO}$ nanoparticles on soil microbial community in different types of soil. Geoderma 352, 204-212.

Kõljalg, U., Nilsson, H.R., Abarenkov, K., Tedersoo, L., Taylor, A.F.S., Bahram, M., Bates, S.T., Bruns, T.D., Bengtsson-Palme, J., Callaghan, T.M., Douglas, B., Drenkhan, T., Eberhardt, U., Dueñas, M., Grebenc, T., Griffith, G.W., Hartmann, M., Kirk, P.M., Kohout, P., Larsson, E., Lindahl, B.D., Lücking, R., Martín, M.P., Matheny, P.B., Nguyen, N.H., Niskanen, T., Oja, J., Peay, K.G., Peintner, U., Peterson, M., Põldmaa, K., Saag, L., Saar, I., Schüßler, A., Scott, J.A., Senés, C., Smith, M.E., Suija, A., Taylor, D.L., Telleria, M.T., Weiss, M., Larsson, K.H., 2013. Towards a unified paradigm for sequence-based identification of fungi. Mol. Ecol. 22 (21), 5271-5277.

Lan, G., Li, Y., Lesueurd, D., Wu, Z., Xie, G., 2018. Seasonal changes impact soil bacterial communities in a rubber plantation on Hainan Island, China. Sci. Total Environ. 626, 826-834.

Langille, M.G.I., Zaneveld, J., Caporaso, J.G., Mcdonald, D., Knights, D., Reyes, J.A., Clemente, J.C., Burkepile, D.E., Vega, R.L., Knight, T.R., Beiko, R.G., Huttenhower, C., 2013. Predictive functional profiling of microbial communities using $16 \mathrm{~s}$ rRNA marker gene sequences. Nat. Biotechnol. 31 (9), 814-821.

Lei, C., Sun, Y., Tsang, D.C.W., Lin, D., 2018. Environmental transformations and ecological effects of iron-based nanoparticles. Environ. Pollut. 232, 10-30.

Li, F., 2017. Reconstruction and Analysis of Genome-Scale Metabolic Models for Microbes in Ammonia Oxidation. Dissertation of Master. Tianjin University.

Liu, Y., Baas, J., Peijnenburg, W.J.G.M., Vijver, M.G., 2016. Evaluating the combined toxicity of cu and ZnO nanoparticles: utility of the concept of additivity and a nested experimental design. Environ. Sci. Technol. 50 (10), 5328-5337.
Liu, Y., Vijver, M.G., Pan, B., Peijnenburg, W.J.G.M., 2017. Toxicity models of metal mixtures established on the basis of "additivity" and "interactions". Front. Environ. Sci. Eng 11 (2), 10

Liu, S., Liu, Y., Pan, B., He, Y., Li, B., Zhou, D., Xiao, Y., Qiu, H., Vijver, M.G., Peijnenburg W.J.G.M., 2020. The promoted dissolution of copper oxide nanoparticles by dissolved humic acid: copper complexation over particle dispersion. Chemosphere 245, 125612.

Quast, C., Pruesse, E., Yilmaz, P., Gerken, J., Schweer, T., Yarza, P., Peplies, J., Glöckner, F.O. 2013. The SILVA ribosomal RNA gene database project: improved data processing and web-based tools. Nucleic Acids Res. 41, 590-596.

Raliya, R., Tarafdar, J.C., 2013. ZnO nanoparticle biosynthesis and its effect on phosphorous-mobilizing enzyme secretion and gum contents in Clusterbean (Cyamopsis tetragonoloba L.). Agric. Res. 2 (1), 48-57.

Rizwan, M., Ali, S., Qayyum, M.F., Ok, Y.S., Adrees, M., Ibrahim, M., Zia-ur-Rehman, M., Farid, M., Abbas, F., 2017. Effect of metal and metal oxide nanoparticles on growth and physiology of globally important food crops: a critical review. J. Hazard. Mater. 322 (Pt A), 2-16.

Rosling, A., Timling, I., Taylor, L., 2013. Archaeorhizomycetes: Patterns of distribution and abundance in soil, in: Horwitz, B., Mukherjee, P., Mukherjee, M., Kubicek, C. (Eds.), Genomics of Soil \& Plant Associated Fungi. Springer, Berlin, pp. 333-349.

Schmidt, M.W., Torn, M.S., Abiven, S., Dittmar, T., Guggenberger, G., Janssens, I.A., Kleber, M., Kögel-Knabner, I., Lehmann, J., Manning, D.A., Nannipieri, P., Rasse, D.P., Weiner, S., Trumbore, S.E., 2011. Persistence of soil organic matter as an ecosystem property. Nature 478, 49-56.

Sekler, I., Sensi, S.L., Hershfinkel, M., Silverman, W.F., 2007. Mechanism and regulation of cellular zinc transport. Mol. Med. 13 (7-8), 337-343.

Shah, V., Jones, J., Dickman, J., Greenman, S., 2014. Response of soil bacterial community to metal nanoparticles in biosoilds. J. Hazard. Mater. 274, 399-403.

Tuomisto, H., 2010. A consistent terminology for quantifying species diversity? Yes, it does exist. Oecologia 164 (4), 853-860.

Wang, W., Hong, J., 2015. Microbiology. China Agricultural University Press, Beijing.

Wang, Z., Zhang, L., Zhao, J., Xing, B., 2016. Environmental processes and toxicity of metallic nanoparticles in aquatic systems as affected by natural organic matter. Environ. Sci. Nano 3 (2), 240-255.

Wyszkowska, J., Borowik, A., Kucharski, M., Kucharski, J., 2013. Effect of cadmium, copper and zinc on plants, soil microorganisms and soil enzymes. J. Elem. 18 (4), 769-796.

Xu, C., Peng, C., Sun, L., Zhang, S., Huang, H., Chen, Y., Shi, J., 2015. Distinctive effects of $\mathrm{TiO}_{2}$ and $\mathrm{CuO}$ nanoparticles on soil microbes and their community structures in flooded paddy soil. Soil Biol. Biochem. 86, 24-33. 